\title{
DronAway: A Proposal on the Use of Remote Sensing Drones as Mobile Gateway for WSN in Precision Agriculture
}

\author{
Laura García $^{1,2}$, Lorena Parra ${ }^{1,3}$, Jose M. Jimenez ${ }^{1,2, *\left(\mathbb{C}, \text { Jaime Lloret }^{1} \mathbb{1} \text {, Pedro V. Mauri }\right.}{ }^{3}$ \\ and Pascal Lorenz ${ }^{2}$ (D) \\ 1 Instituto de Investigación para la Gestión Integrada de zonas Costeras, Universitat Politècnica de València, \\ 46730 Grau de Gandia, Spain; laugarg2@teleco.upv.es (L.G.); loparbo@doctor.upv.es (L.P.); \\ jlloret@dcom.upv.es (J.L.) \\ 2 Network and Telecommunication Research Group, University of Haute Alsace, 34 rue du Grillenbreit, \\ 68008 Colmar, France; pascal.lorenz@uha.fr \\ 3 Instituto Madrileño de Investigación y Desarrollo Rural, Agrario y Alimentario (IMIDRA), Finca "El Encin", \\ A-2, Km 38, 2, Alcalá de Henares, 28800 Madrid, Spain; pedro.mauri@madrid.org \\ * Correspondence: jojiher@dcom.upv.es
}

Received: 28 August 2020; Accepted: 22 September 2020; Published: 24 September 2020

\begin{abstract}
The increase in the world population has led to new needs for food. Precision Agriculture (PA) is one of the focuses of these policies to optimize the crops and facilitate crop management using technology. Drones have been gaining popularity in PA to perform remote sensing activities such as photo and video capture as well as other activities such as fertilization or scaring animals. These drones could be used as a mobile gateway as well, benefiting from its already designed flight plan. In this paper, we evaluate the adequacy of remote sensing drones to perform gateway functionalities, providing a guide for choosing the best drone parameters for successful WiFi data transmission between sensor nodes and the gateway in PA systems for crop monitoring and management. The novelty of this paper compared with existing mobile gateway proposals is that we are going to test the performance of the drone that is acting as a remote sensing tool to carry a low-cost gateway node to gather the data from the nodes deployed on the field. Taking this in mind, simulations of different scenarios were performed to determine if the data can be transmitted correctly or not considering different flying parameters such as speed (from 1 to $20 \mathrm{~m} / \mathrm{s}$ ) and flying height (from 4 to $104 \mathrm{~m}$ ) and wireless sensor network parameters such as node density (1 node each $60 \mathrm{~m}^{2}$ to 1 node each $5000 \mathrm{~m}^{2}$ ) and antenna coverage ( 25 to $200 \mathrm{~m}$ ). We have calculated the time that each node remains with connectivity and the time required to send the data to estimate if the connection will be bad, good, or optimal. Results point out that for the maximum node density, there is only one combination that offers good connectivity (lowest velocity, the flying height of $24 \mathrm{~m}$, and antenna with $25 \mathrm{~m}$ of coverage). For the other node densities, several combinations of flying height and antenna coverage allows good and optimal connectivity.
\end{abstract}

Keywords: drone; remote sensing; sensor network; WiFi; precision agriculture

\section{Introduction}

The continued increase of the world population and its need for food, as well as the decrease in natural resources, has led to the necessity of making great changes in agriculture. Farmers and agricultural workers must implement measures to improve and control the state of crops and to optimize the utilized resources. In many countries, farmers are opting to implement solutions that apply technological means. For example, the European Union (EU) established in its 2020 strategy 
policies such as the Common Agricultural Policy (CAP) [1], which responds to the new economic, social, environmental, and technological challenges facing our society, and as a result, it contributes to its development. One of those policies has its focus on Precision Agriculture (PA). PA consists of observing, measuring, and acting on crops, regardless of the conditions of the site and utilizing certain technologies [2,3]. Authors such as [4] present PA as a systematic process that covers data collection, diagnostics, data analysis, and precision field operation and evaluation. As a result, decision making is simplified and better adapted to the ideal solution, leading to obtaining better results.

One of the technologies that is being utilized the most in PA implementations is sensor node systems. The advantage of these devices is that they can capture information to observe a large number of environmental parameters $24 \mathrm{~h}$ a day, 365 days a year, and their values can be monitored in real time if necessary. The information can be stored and transmitted at any time, based on the developed system and the needs of crop control as long as there is an Internet connection in the deployed area.

Gateways in PA systems can be deployed on different manners, i.e., on poles, on trees, on moving machinery such as tractors of pivot-center irrigation structures, and on drones. For the cases where the gateway is located on a static position (poles and trees), the network would require a larger number of gateways to cover the expanse of the fields. Using moving manned vehicles and irrigation structures would be possible for crops that require those vehicles to go through the fields often enough or to be irrigated using pivot-center structures regularly. However, drones can be utilized in more comprehensive types of crops and are not restricted to specific moments of the plant growth where the machinery is necessary. It also allows reducing the cost as only one gateway is required.

The use of drones, also known as Unmanned Aerial Vehicles (UAVs) in the military field or Remotely Piloted Aircraft (RPA), has been increasing in the recent years due to the improvement in design and accessibility. Drones are primarily used to perform remote sensing and can capture photographs and videos to send them in real time or to store for later analysis. These images can be utilized to perform mapping, navigation, and georeferencing [5] for applications such as agriculture, forestry, surveillance, location and rescue, environmental monitoring, photogrammetry, vegetation analysis, atmospheric monitoring, wildlife conservation, cultural heritage conservation, and urban environment monitoring [6]. In precision agriculture, remote sensing can be used to monitor growth vigor, drought stress, and nutrients, to detect weeds and pathogens, and to perform yield prediction using multispectral, hyperspectral, RGB (Red, Green, Blue), and thermal sensors [7]. Their use is being extended to the implementation of smart systems such as the system proposed in [8] where a drone took pictures of palm trees and communicated with smart insect traps to spray insecticide. They can also be used as tools for treatments with fertilizers or phytosanitary products or even to scare away birds. The agriculture drones market size is expected to grow from USD 1.2 billion by 2019 to USD 4.8 billion by 2024 at a CAGR (Compound Annual Growth Rate) of 31.4\% [9].

Contemplating the increase in the use of drones for precision agriculture remote sensing activities, adding new functionalities to benefit from the itinerary of the drone is an aspect to consider. Precision agriculture includes the use of WSNs (Wireless Sensor Networks) as well. The design of these WSNs can vary depending on the node density, on the topology, or the communication technology. However, using the UAVs currently employed for image and video capture of the crops as a mobile gateway to gather the data from the sensor nodes deployed on the field is a solution to consider. These drones already have a flight plan designed to capture the required images to map the fields or detecting diseases, pests, or water stress on the plants. Furthermore, significant efforts have been made for implementing low-cost PA solutions in developing countries, in which the internet connection might not be as extended as in developed countries. In these cases, we can use the drone, which has an internet connection, to serve as a mobile gateway for the WSN deployed in the soil. Nevertheless, aspects such as the required flight height and speed to ensure good image captures as well as local regulations and the characteristics of the drone have to be considered. It is important to note that the flying parameters of the drone have been set to optimize the process of gathering pictures or video, and those parameters cannot be modified. 
In this paper, we evaluate the adequacy of remote sensing drones to perform gateway functionalities for a WSN deployed on the soil, providing a guide for choosing the best drone parameters for successful data transmission between sensor nodes and the gateway. In order to do so, we consider the scenario of precision agriculture fields where an imaging drone is already being used for imaging purposes. This situation can be challenging, as the existing flight plan limits the time the drone can keep the node within its coverage area. The drone carries the node that acts as a gateway and gathers the data from the nodes while the drone performs its imaging functions. Furthermore, we have presented the required architecture and algorithms for our proposal. To ensure that the drone can be used as a mobile gateway, several configurations have been simulated for the scenario, considering WSN and drone parameters. We have considered the flying height and velocity for the drone. On the other hand, we have selected different node densities and antenna coverage as WSN parameters. With the flying height and antenna coverage, we have determined if the node has coverage or not. Including the flying velocity, we calculated, using the sagitta of the circular arch equations, the time in coverage for each node. Then, considering the minimum required time to send data and the number of nodes, the feasibility of connection is determined for each possible combination of mentioned parameters.

The rest of the paper is organized as follows. Section 2 presents related work. The theoretical framework and background are presented in Section 3. The description of the scenario and the proposed algorithm are presented in Section 4. The results are discussed in Section 5. Finally, the conclusion and future work are presented in Section 6.

\section{Related Work}

Drones have been utilized for remote sensing activities for different purposes in vegetated areas. Andrew M. Cunlife et al. presented [10] a remote-sensing dryland vegetation quantification technique. The technique was able to employ structure-from-motion (SfM) photogrammetry of pictures taken from drones to obtain 3D models of the vegetation structure. The technique was able to identify grass tussocks with volumes of a few $\mathrm{cm}^{3}$ employing canopy height models. The results showed that the technique was able to predict biomass utilizing the detected canopy volume, obtaining coefficients of determination that ranged from 0.64 to 0.95 . Moreover, Jian Zhuang et al. [11] proposed the use of lightweight drones for the remote sensing of forests for ecological purposes. The system employed drone-derived canopy variables to detect patterns in the biodiversity of the forest. Results showed a correlation between canopy closure and stand basal area. Niche differentiation was performed utilizing edaphic and topographic variables. Lastly, the authors detected a correlation between canopy variables and light-demanding species. Urbahs et al. [12] described the structural characteristics and the parameters of a UAV developed for its use in environmental monitoring. Paulina Lyubenova Raeva et al. [13] presented a study in which a drone was utilized to obtain vegetation indexes and thermal maps, relating the temperature of the vegetation and the soil. In order to do so, they used multispectral and thermal sensors. Stehr et al. [14] assured that drones could monitor the fields more frequently than the satellites. They also stated that drones could take more detailed photographs, and clouds do not hinder their vision. They also predicted that at the time when the cost of drones decreases and their technology improves, more drones would be used in the field of agriculture. Furthermore, Kurkute et al. [15] described the process of developing a mechanism for spraying from a drone.

Other authors such as Puri et al. [16] made a study where they presented the best drones that can be used in monitoring and observation in agriculture so as to improve crops and prevent damage to the fields.

Valente et al. [17] presented a collaborative system consisting of a WSN and an aerial robot that was used for the real-time monitoring of frost in vineyards. Its solution was a mobile node that transported an aerial robot that ensured communication between the dispersed nodes and the base station of the robot. This method allowed them to overcome the limitations arising from the use of wireless networks. 
There are authors, such as the following, who present a classification of UAV applications in PA. Hunt et al. [18] present a classification of the applications of the unmanned aircraft systems (UAS) for precision agriculture. The authors define the following three niches or sectors in their classification: scouting for problems, monitoring to prevent yield loss, and planning crop management operations. Tsouros et al. [19] review recent applications of UAVs for Precision Agriculture. Rao Mogili et al. briefly review the implementation of UAVs for crop monitoring and pesticide spraying. Daponte et al. [20] propose a survey on techniques, applied to precision agriculture monitoring, through the use of drones equipped with multispectral, thermal, and visible cameras. For each application, the main limitations are highlighted, and the parameters that need to be considered before performing a flight are reported.

Authors such as Boehm et al. [21] propose using an IEEE802.11n network to distribute the images captured from a UAV to their ground control station.

Furthermore, fields and remote areas can hinder the progress of other activities such as cultural heritage conservation, and drones have been considered as a solution to implement systems such as the remote-sensing system for an archaeological survey of remains in mountain areas presented by Tesse D. Stek [22]. The author concludes that the use of drones can substantially improve the surveying process of archaeological projects adding to the on-site activities. Furthermore, remote sensing provides advantages such as being non-destructive, reducing the time and cost of the surveyance process, and the ability to access areas located on agricultural fields with difficult access and fields where the farmer or the proprietor must grant the access.

The vegetation can also be in urban environments. For that reason, José Marín et al. presented in [23] a remote sensing system for urban lawn monitoring in smart cities. The system is comprised of an Arduino node with a camera mounted on a drone. Photographs are taken and classified into different grass qualities employing a rule-based algorithm that classify the grass into very low, low, and high coverage. The system was tested with a dataset of grass pictures resulting in success in the classification of $100 \%$. Lastly, the authors concluded that their system reduced the execution time of the process of taking pictures of the garden, compared to the same classification system mounted on a vehicle, for areas larger than $1000 \mathrm{~m}^{2}$.

Sensor nodes are a widely spread technology utilized in many agricultural monitoring systems to implement their solutions.

Some authors have presented a review of the state of the art of the use of Wireless Sensor Networks (WSN) in agriculture [24-28]. Tamoghna Ojha et al. [24] studied applications of WSN and its problems and challenges for the improvement of agriculture. Antonis Tzounis et al. [25] presented a survey on the latest IoT technologies and their implementation in the agricultural sector, as well as the challenges that arise in their implementation. Aqeel-ur-Rehman et al. [26] studied the need of using sensors in agriculture and the utilization of WSN in that field. Luis Ruiz-Garcia et al. [27] reviewed wireless sensor technologies and standards for their communications in the agri-food sector, focusing on WSN and Radio Frequency Identification (RFID). Barcelo-Ordinas et al. [28] also presented the state of the art of WSN technology applied to precision agriculture, reporting hardware and software solutions from the technological point of view.

Other authors presented designs for new WSN architectures for agriculture [29-31]. Authors such as Srbinovska et al. [29] proposed a WSN architecture for a greenhouse of vegetables, achieving the monitoring of environmental parameters in crops and a reduction in costs. Xiaoqing Yu et al. [30] presented a hybrid WSN architecture applied to agriculture. A hybrid network of wireless sensors consists of wireless sensors that communicate through the ground in addition to wireless terrestrial sensors. Chaudhary et al. [31] have proposed and analyzed a programmable on-chip (PSoC) microcontroller that they integrate into a WSN network and use to monitor and control parameters in greenhouses.

Furthermore, there are authors [32-37] that present monitoring systems in agriculture based on WSN. Escolar Díaz et al. [32] proposed a methodology to implement WSN in agriculture and define the phases that cover the life cycle of WSN applications. Yingli Zhu et al. [33] presented the design of a 
real-time agricultural monitoring system based on WSN. They also provided the hardware design of the sensors and the software flow diagram. Manijeh Keshtgari and Amene Deljoo [34] also developed a WSN system for agriculture through which they detected environmental data and made control decisions in real time. Hwang et al. [35] proposed a monitoring system for agriculture that used a WSN, which collected soil and environmental information through sensors, image information using CCTV (Closed-Circuit Television), and finally GPS (Global Positioning System) location information. Garcia-Sanchez et al. [36] proposed a new platform called Integrated WSN Solution for Precision Agriculture, in which a WSN is deployed with IEEE 802.15.4 technology. It allowed the monitoring of the crop and its video surveillance. Garcia et al. [37] presented the design of a wireless network that was responsible for monitoring the crops and their irrigation system; the network consisted of a WSN and a wireless mesh network (WMN).

Existing works have studied the use of drones for imaging in precision agriculture [10-13], the transmission of video images to a ground station [21], and the data acquisition of nodes deployed in remote areas for different types of purposes such as urban lawn monitoring [23] or archaeological projects [22]. Other works focus on the exclusive use of drones as a gateway with specially designed flight plans that determine the shortest flight necessary to fly over all the nodes or has the drone hovering over the node for more than a minute until all the data are transmitted [17]. In our work, we consider the challenge that is generated when combining both functionalities by contemplating the use of remote sensing drones as gateways for WSNs in precision agriculture. A remote sensing drone already has a defined flight plan to map the fields or perform pest or disease detection. Then, the gateway node is presented with the challenge of gathering the data in a short time as the drone does not circle or hover over the node on the field. Considering these restrictions, this work provides a guide to determine the best coverage time for the communication between sensor nodes and a drone where we define the speed and height at which the drone moves so that the collection of data obtained from the sensor nodes is reliable. As far as we know, the combined use of a single drone as a mobile gateway while maintaining the flying parameters previously set for picture gathering has not been presented.

\section{Materials and Methods}

In this section, the parameters and elements considered to perform our guide are explained. In the first subsection, an overview of the available types of drones that can be utilized in PA and the description of the flight plan of the considered scenario is provided. In the second subsection, the characteristics of commercial nodes that can be utilized for our proposed scenario are detailed. In the third subsection, the background on the antenna radiation model and the best antenna types for the scenario are presented. Furthermore, the theoretical framework used to perform the calculations is described.

\subsection{Drone Parameters}

Drones in PA have been mainly used for remote sensing by image gathering. However, drones can be utilized as well for data gathering of nodes deployed on the field. These drones can have fixed or rotary wings, which determines how they fly as well as other parameters such as the ones detailed in Table 1.

Table 1. Characteristics of commercial drones for PA systems.

\begin{tabular}{|c|c|c|c|c|c|c|}
\hline Drone & $\begin{array}{l}\text { Nominal } \\
\text { Endurance }\end{array}$ & Cruise Speed & $\begin{array}{l}\text { Typical Climbing } \\
\text { Speed }\end{array}$ & $\begin{array}{l}\text { Max Wind } \\
\text { Speed }\end{array}$ & $\begin{array}{l}\text { Typical Range } \\
\text { Altitude }\end{array}$ & Wing Type \\
\hline Swinglet [38] & $30 \mathrm{~min}$ & $10 \mathrm{~m} / \mathrm{s}$ & $3 \mathrm{~m} / \mathrm{s}$ & $7 \mathrm{~m} / \mathrm{s}$ & $20-500 \mathrm{~m}$ & Fixed \\
\hline Phantom 3 advanced [8] & $23 \mathrm{~min}$ & $16 \mathrm{~m} / \mathrm{s}$ & $5 \mathrm{~m} / \mathrm{s}$ & - & $120 \mathrm{~m}$ & Rotatory \\
\hline
\end{tabular}

Fixed-wing drones can fly for hours and long distances on a limited amount of energy [40], which makes them popular for Precision Agriculture purposes, including taking pictures of the fields, 
as it provides good autonomy. However, stationary flights are not possible with fixed-winged drones. Furthermore, this type of drone requires a drone catapult to launch it if a person cannot do it, and a big enough surface for landing.

On the other hand, rotatory-winged drones are the most common. They can stay in one place to perform inspection activities. This type of drone is available with 3 to 8 motors. They can take off and land vertically. However, these drones have less autonomy with endurance below $1 \mathrm{~h}$. Other solutions opt for using their developed drone [41]. This allows detailed customization of the UAV for the required PA solution.

The intended purpose of the drone will determine its flight plan. For the drone to carry a node that acts as a gateway, the drone must be in the area of coverage of the node long enough for all the data to be transmitted. For small amounts of data, a straight flight plan where the nodes are flown over can work. However, for significant amounts of data, flight plans where the drone circles the node until all the data is transmitted may be necessary [42]. In Figure 1, these two types of flight plans are shown. In the scenario considered in this paper, the flight plan follows straight lines that fly over the nodes deployed on the field. The flight plan that circles the node for a fixed-wing drone or hovering over the nodes for a quadcopter would solve the problem of having enough connection time to perform the connection and transmit all the data before the node is out of the coverage area of the drone. However, as previously stated, in this paper, we consider the challenge presented by the scenario where an imaging drone that has a previously defined flight plan that covers the field following straight lines while carrying the gateway node.

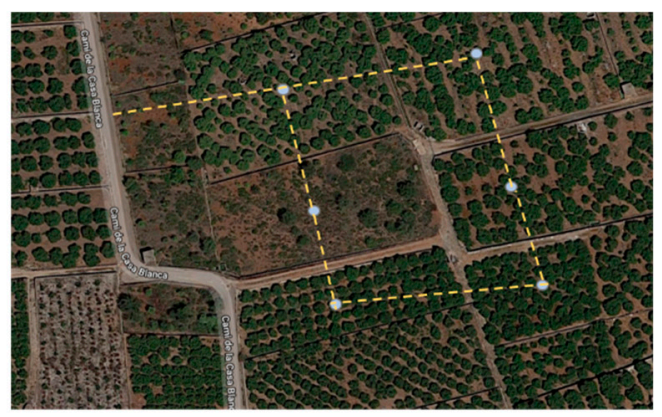

a)

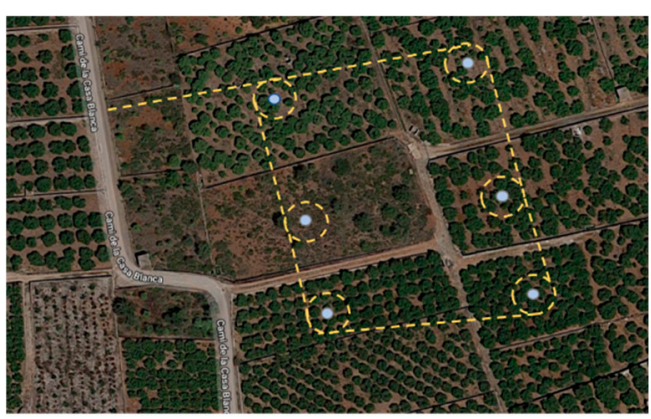

b)

Figure 1. (a) Flight plan with straight lines, (b) Flight plan circling the nodes.

Furthermore, each country has its regulations for drones. Some countries require obtaining a license that may distinguish between recreational and professional use. The height, areas allowed for flights, and weight of the drone may also be restricted depending on the type of license.

\subsection{Low-Cost Nodes for Precision Agriculture Deployments}

Nowadays, there is a wide variety of low-cost nodes that can be employed for PA purposes using WiFi communication. Some of the most utilized ones are presented in Table 2. In the scenario contemplated in this paper, low-cost nodes are utilized both for the field monitoring and for the gateway mounted on the drone. As can be seen, the characteristics of the nodes can vary greatly. The weight and size of the nodes should be considered to determine if the chosen drone would be affected by it or if it is able to carry the node without interfering with its flight. If no sensors are connected to the node carried by the drone and big processing capacity is not necessary, nodes such as the WEMOS MINI D1 would be best to reduce the energy consumption due to its low weight and size. 
Table 2. Characteristics of popular nodes for Precision Agriculture (PA) systems.

\begin{tabular}{cccccccc}
\hline Controller & FLASH & RAM & EEPROM & Weight & Size & Operating Voltage & Reference \\
\hline WEMOS MINI D1 & $4 \mathrm{MB}$ & - & - & $3 \mathrm{~g}$ & $34.2 \times 25.6 \mathrm{~mm}$ & $3.3 \mathrm{~V}$ & {$[43]$} \\
Node MCU & $4 \mathrm{MB}$ & $520 \mathrm{kB}$ & - & $10 \mathrm{~g}$ & $48 \times 26 \times 11.5 \mathrm{~mm}$ & $3.3 \mathrm{~V}$ & {$[44]$} \\
Arduino Mega & $256 \mathrm{kB}$ & $8 \mathrm{kB}$ & $4 \mathrm{kB}$ & $37 \mathrm{~g}$ & $101.52 \times 53.3 \mathrm{~mm}$ & $5 \mathrm{~V}$ & {$[45]$} \\
Arduino UNO & $32 \mathrm{kB}$ & $2 \mathrm{kB}$ & $1 \mathrm{kB}$ & $25 \mathrm{~g}$ & $68.6 \times 53.4 \mathrm{~mm}$ & $7-12 \mathrm{~V}$ & {$[46]$} \\
Raspberry Pi 3 Model B+ & - & $1 \mathrm{~GB}$ & - & $50 \mathrm{~g}$ & $85 \times 56 \times 17 \mathrm{~mm}$ & $5 \mathrm{~V}$ & {$[47]$} \\
\hline
\end{tabular}

Other wireless technologies such as LoRa and 5G would reduce the need for using drones for data collection or completely eliminate it in small fields due to their wider range. However, these technologies are more costly, and therefore, they are less accessible for farmers with lower budgets.

Furthermore, multiple parameters can affect the communication system, such as the transmitted power, the protocol, or the link budget. Regarding the transmitted power parameter, it would fundamentally affect the drone coverage, as it would consume a greater amount of energy, and its flight capacity would be reduced. Using different protocols would affect the total connection time since, depending on the transitions between different states, which are associated with the actions implemented by the nodes, the connection time necessary between the nodes and the drone can be altered. On the other hand, the link budget would be defined as an addition of transmitted power and gains minus the losses. The received power is based on the losses, which occur when the signal is transmitted through the medium and can be affected by aspects such as the weather or the objects that interrupt the line of sight between the emitter and the receiver. However, in the studied scenario, there are no objects between the emitter and the receiver, and the drone would not fly with adverse weather conditions. Therefore, in this scenario, the losses would be constant. Lastly, the transmitted power and the gains will be based on the antennas and their configuration and, therefore, they would not vary unless different types of antennas or nodes with their configuration were used in order to increase the transmitted signal.

\subsection{Antenna Radiation Model}

There are many types of antennas available to transmit at the $2.4 \mathrm{GHz}$ band. However, not all of them are advised for the scenario of a gateway carried on a drone. In Figure 2, the Theoretical WiFi Coverage Area (TWCA) and the Assumed WiFi Coverage Area (AWCA) for both an omnidirectional and a directional antenna are displayed. Common radiation patterns for both antennas are displayed as well. For the scenario, the gateway node is considered to be carried by the drone, placed in a manner so that the antenna emits its energy in a downward direction, toward the earth. For the case of the directional antenna, the radiated energy is focused on a specific direction. Whenever the gain of a directional antenna increases, the coverage distance increases, but the effective angle of coverage decreases [48]. On the other hand, omnidirectional antennas have a radiation pattern that is given based on the directive gain. This type of antenna provides uniform radiation in one of the reference planes. Therefore, regarding directivity, omnidirectional antennas are better suited for the scenario as it allows the node to be in the coverage area of the gateway for a longer time than that of directional antennas. For other scenarios such as that of a flight plan that circled the nodes on the ground, directional antennas would be a better fit as the drone could remain in a zone where the node is inside the coverage area, and the radiated energy would remain on the intended spot.

Furthermore, the antennas can have linear or circular polarization. Depending on the type of polarization, their coverage area will vary. The polarization of the antennas from both the emitter and receiver should match to avoid loses. In our scenario, the antennas are placed at the same position in a horizontal manner with the same polarization for the antennas of the gateway node on the drone and the nodes on the field.

Some low-cost nodes incorporate built-in WiFi antennas such as the PCB (Printed Circuit Board) antenna, while others need a communication module or an external antenna, such as a whip antenna, to provide better performance. The antenna gain and the selected transmission power determine the 
Coverage Radius (CR). Therefore, it is essential to determine the distance that must be covered to select the antenna. For lower flying heights, the required coverage radius is lower, and the built-in PCB antenna has been utilized in IoT (Internet of Things) applications for distances up to $30 \mathrm{~m}$ in most low-cost modules for RSSI (Received Signal Strength Indicator) values below $-80 \mathrm{~dB}$ and up to $120 \mathrm{~m}$ for the best performing module [49]. For higher flying heights, the area to be covered is wider, and whip antennas would provide better performance, but its size is bigger, and it should be placed in a manner not to interfere with the flight of the drone.
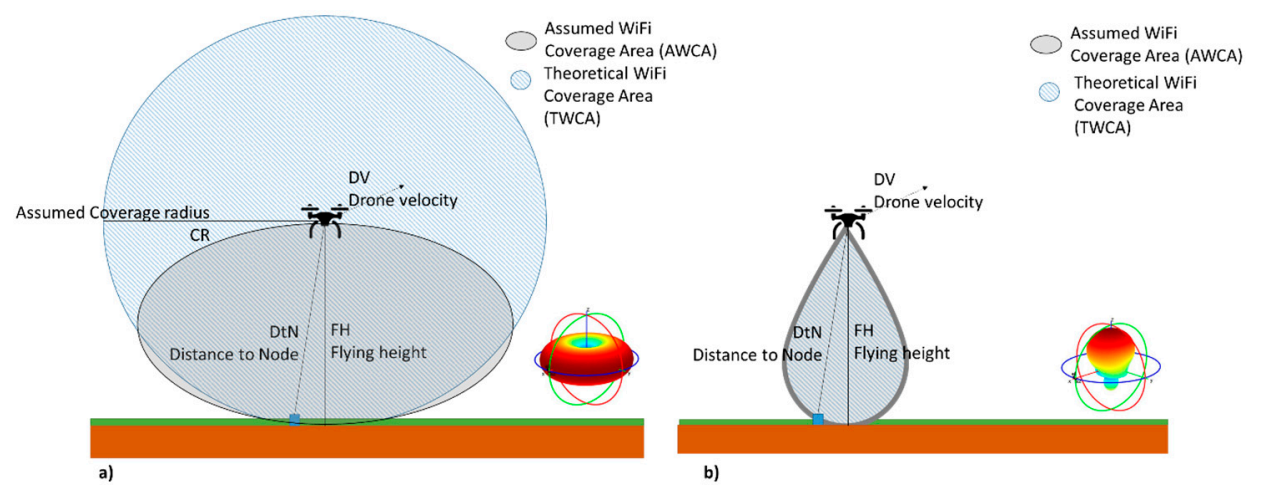

Figure 2. Area covered by the sensor antenna located on the drone: (a) Omnidirectional antenna case, (b) Directional antenna case.

From the point of view of the node in the soil, the radiation pattern of the gateway in the drone can be compared with a sphere. Based on this assumption, we can use a trigonometrical problem to calculate the time for which a single node has a wireless connection to the mobile gateway in different scenarios (different drone flying height, flying velocities, etc.).

The concept of sagitta (s) of a circular arc is widely used in architecture and optics. The sagitta of a circular arc is the distance from the center of the arc to the center of its base; see Figure 3.

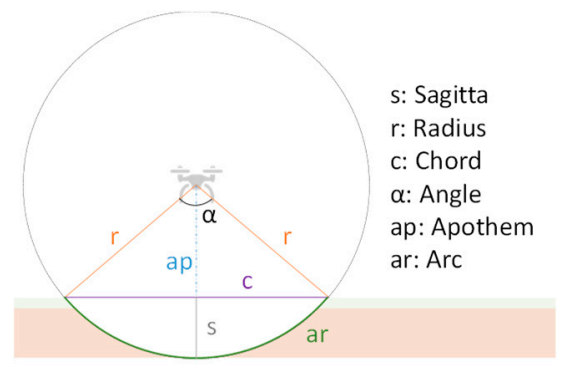

Figure 3. Sagitta of the circular arch described by the coverage of the drone.

The mathematical equations of this problem are Equations (1)-(7). The $s$ can be calculated as the difference between the radius $(r)$ and the apothem (ap); see Equation (1). According to the Pythagorean Theorem, $s$ can also be calculated as a function of $r$ and chord (c); see Equation (2). Moreover, it is possible to apply the versine function to obtain the value of $s$ according to Equation (3) where $\alpha$ is the angle formed by the two $r$, which forms the triangle with the $c$. Alternatively, there is one last method to calculate the $s$; see Equation (4).

$$
\begin{gathered}
s=r-a p \\
s=r-\sqrt{r^{2}-\left(\frac{c}{2}\right)^{2}} \\
s=r x \operatorname{versin} \frac{\alpha}{2}=r x\left(1-\cos \left(\frac{\alpha}{2}\right)\right)
\end{gathered}
$$




$$
s=\frac{c}{2} x \tan \frac{\alpha}{2}
$$

In our problem, the ap represents the flying height $(f h), r$ is the radius of the drone coverage $(d c)$, and the chord represents the coverage in the soil. The known variables are $f h$ and $d c$, and our objective is to calculate the value of $c$. Therefore, the employed equations in our calculations will be Equations (1)-(2). Combining them, we can obtain Equation (5), which can be expressed as Equation (6) to obtain the value of $c$. Finally, considering the flying velocity $(f v)$, we can calculate the time $(t)$ during which a single node has coverage from the gateway mounted on the drone (Equation (7)).

$$
\begin{gathered}
d c-f h=d c-\sqrt{d c^{2}-\left(\frac{c}{2}\right)^{2}} \\
c=2 \sqrt{d c^{2}-(-f h)^{2}} \\
t=\frac{2 \sqrt{d c^{2}-(-f h)^{2}}}{d v}
\end{gathered}
$$

Now, we can use Equation (7) to calculate the time during which a node has coverage for different scenarios. In our calculations, we include values of $d c$, fh, and $f v$, which can be found in real applications. The selected values are $d c$ from 200 to $25 \mathrm{~m}$, fh from 5 to $100 \mathrm{~m}$, and fo from 5 to $20 \mathrm{~m} / \mathrm{s}$.

\section{System Description}

One of the main problems in the considered scenario is that the drones may face collisions between the sensor nodes located within the coverage range of the drone. To solve this problem, in this section, we propose a data acquisition system for precision agriculture deployments where the sensor nodes forward the data to one sole mobile gateway mounted on a remote sensing drone. The architecture of the specific precision agriculture scenario is discussed as well.

\subsection{Architecture}

The architecture of the precision agriculture scenario is divided into four layers, which are the Sensor Node Layer, the Drone Layer, the Internet Layer, and the Data Center Layer. Figure 4 shows the different layers.

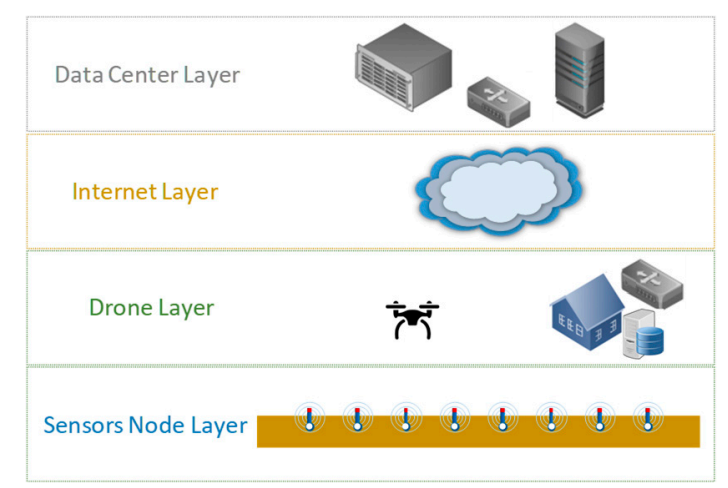

Figure 4. Architecture layers.

The Sensors Node Layer is the bottom layer. All the sensor nodes deployed in the crops are located in this layer. The layer immediately above is the Drone Layer. It is comprised of the remote sensing drone that is responsible for obtaining images of the crops and collecting the information stored by the nodes through its wireless interface, the location where the drone has their base station, the IT equipment where the information that the drone has collected during its flight is stored, and the network devices that allow us to connect to the Internet. The connection to the Internet is performed 
by employing a Service Provider. Depending on the location of the crop fields, the technology used to connect to the Internet may vary, choosing among cable or wireless technologies to establish the connections. The following layer is the Internet. The Internet is accessed through the Operator to send all the acquired data to a remote location, where the information will be processed. The connection to the remote location is made by establishing a Virtual Private Network (VPN). This way, the data will be protected when crossing the Internet. Finally, the Data Center Layer, where we store the obtained information, is located at the remote location. This information can be processed using Artificial Intelligence (AI) to ensure that decision making is optimal.

\subsection{Algorithm}

In this subsection, the functioning algorithm for both the drone and the field nodes is explained. Furthermore, the message exchange between the elements of the architecture is presented as well.

The PA scenario is comprised of multiple sensor nodes deployed in several agricultural fields. No networking structure is established among the nodes. Thus, the nodes do not communicate in any way among themselves. A sensor network where the nodes deployed on the field forward the data through relay nodes located in between the soil monitoring nodes would address the problem of sending the information to the base station, but it would significantly elevate the cost of the deployment-more so for node densities where large distances separate the nodes. The nodes incorporate various soil monitoring sensors that are able to obtain data on the physical parameters necessary to manage and monitor the crops. Depending on the node model, similar to the ones previously presented in Table 2, the node may use an embedded antenna to communicate, or it may need a separate communication module from the ones available on the market. The data are stored in the SD (Secure Digital) cards connected to each one of the nodes until the remote sensing drone retrieves the information. Figure 5 presents an example of a soil monitoring drone with a temperature and a humidity sensor.

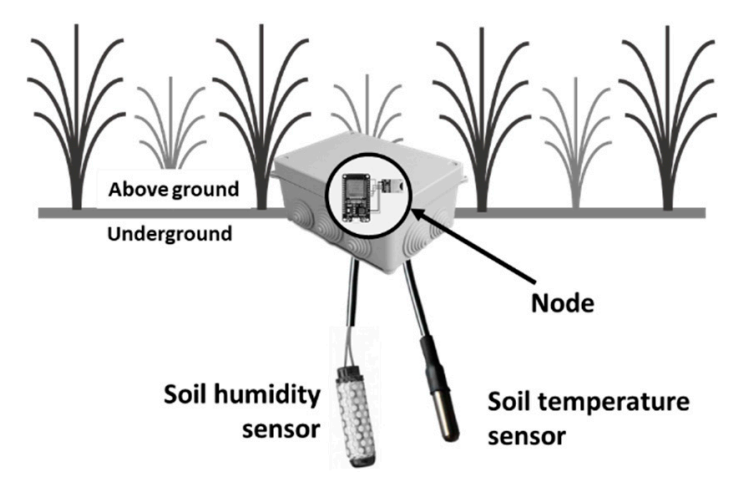

Figure 5. Design example of the soil monitoring node.

The drone is located on a base station, where the route begins and ends. The drone takes photographs of the fields and the terrain during its flight. When the drone reaches the base station, all the retrieved information is forwarded to the data center where the information is stored on a database for further analysis.

A connection between the sensor node and the drone, with a good enough quality to ensure that the data is transmitted successfully, is one of the requirements of a PA system that employs a drone to gather data from the sensor nodes deployed on the field. Other requirements include low energy consumption for the drone to complete its route, the availability of the operating frequency band, and good weather conditions to avoid signal attenuation and damages to the drone and sensor nodes.

Regarding the data rate, it is crucial to consider that the parameters measured in PA systems vary at a slow pace. Therefore, continuous monitoring is not necessary, and the data can be captured each minute or at larger time intervals such as 5, 10, or 30-min intervals. Therefore, the information stored in the SD card is not a large amount, and the necessary data rate would hardly surpass 
1 Mbps. Furthermore, works such as [50] show real data rates obtained at different flying heights and distances that surpassed $1 \mathrm{Mbps}$ for heights of $20 \mathrm{~m}$ and distances of $45 \mathrm{~m}$, with the drone acting as an intermediary node and therefore having more chances of experiencing interference and signal attenuation. A fixed-winged drone is utilized in [39] to capture images from the fields and forward them using WiFi, where a UDP (User Datagram Protocol) throughput up to $176 \mathrm{Mbps}$ was obtained from real experiments. Therefore, although parameters such as flying height and speed are undoubtedly determinant in the success of the data transmission, once the connection between the sensor node and the drone is established, the necessary data rate is not high.

Low energy consumption should be sought on both the drone and the sensor nodes. The sensor nodes can go into sleep mode during idle time to reduce energy consumption. Furthermore, if the settings of the drone indicate a fixed time for the drone to gather the data from the sensor nodes, the nodes can activate at that time to avoid being in sleep mode when the drone flies over them. Lastly, the lifetime of sensing nodes can surpass a year if the energy consumption and battery choice are optimized. Using solar panels to power the sensor nodes would even nearly cease the problem of battery-less sensor nodes. Choosing between using batteries or solar power would be determined by the type of crop or the desired size for the sensor node. Trees remain productive each year without needing to plant new ones, but other crops are not used after the harvest, where the field is left to rest until the planting season. Therefore, the nodes could be fixed or be removed and deployed again according to the type of crop and its characteristics.

Most fields are far from populated areas, and interferences from other networks are lower than industrial or urban environments. However, testing the area for other networks is a good practice to choose the best settings and communication technology for the PA system.

Lastly, extreme weather conditions are unavoidable, but some measures can be taken to reduce the damage that can be caused by the elements of the PA system. For example, if a weather station is incorporated into the PA system, the drone could decide whether it is safe or not to fly. The sensor nodes should have a protective encapsulation and be able to store the data of several days to ensure no data is lost. Furthermore, if the drone were to be lost due to extreme wind or rain, the SD cards in the sensor nodes would ensure that the data can be accessed manually.

The information monitored in each one of the sensors is unique, and as we have previously commented, it must be forwarded to a remote location where the data center is deployed. Due to the limitations intrinsic to the deployed network which has a limited processing and storage capacity, limited power availability, and a short time interval for the communication between the node and the drone, we consider a system comprised of soil monitoring nodes. These remote sensing drones obtain video and photographs of the fields and gather the data from the nodes, the base station of the node that includes a gateway to send the data to the remote location, and the data center situated in a remote location where the data is stored and analyzed.

The functioning algorithm of the drone is presented in Figure 6. Firstly, the drone loads the flight plan, which can be designed using the existing software for flight plan designs and considering crop requirements. After the setup, the drone asks for the weather information gathered by the weather station. If the wind speed is greater than the threshold value (wth), the flight is cancelled, and the drone waits until the next scheduled flight. If the wind speed is correct, the rain amount is then checked. If the threshold value (rth) is surpassed, the flight is cancelled as well. If everything is correct, the drone checks the available energy. If there is enough energy, the drone begins the route through the fields. If there is not enough energy, the drone cancels the flight. Then, the drone checks if a node is asking for a connection. If there is no node to connect with, a photo of the field is taken, and the available energy is re-evaluated. When a node is detected, a connection is established, and the drone receives the data. When all the data has been received, the drone sends a disconnect message to the node to indicate that the connection is terminated and that the node should go to sleep mode and should not try to connect to the drone for the time determined in the settings. By doing this, the possible interferences caused by other nodes deployed in the fields in the coverage range of the 
drone are avoided. Although interferences among the nodes for the configurations of node coverages for orchards of fruit-bearing trees, as contemplated in this scenario, would only be possible with the case of 1 node per $60 \mathrm{~m}^{2}$ of node density. The detailed explanation of the different node densities considered for different types of crops is presented in Section 5.1. After that, an oblique photo of the field is retaken, and the drone looks for another node. When the route was finalized, the drone goes to the base station and forwards the data to the database at the remote location for further analysis. Then, the drone waits at the station until the scheduled time for the next flight is reached.

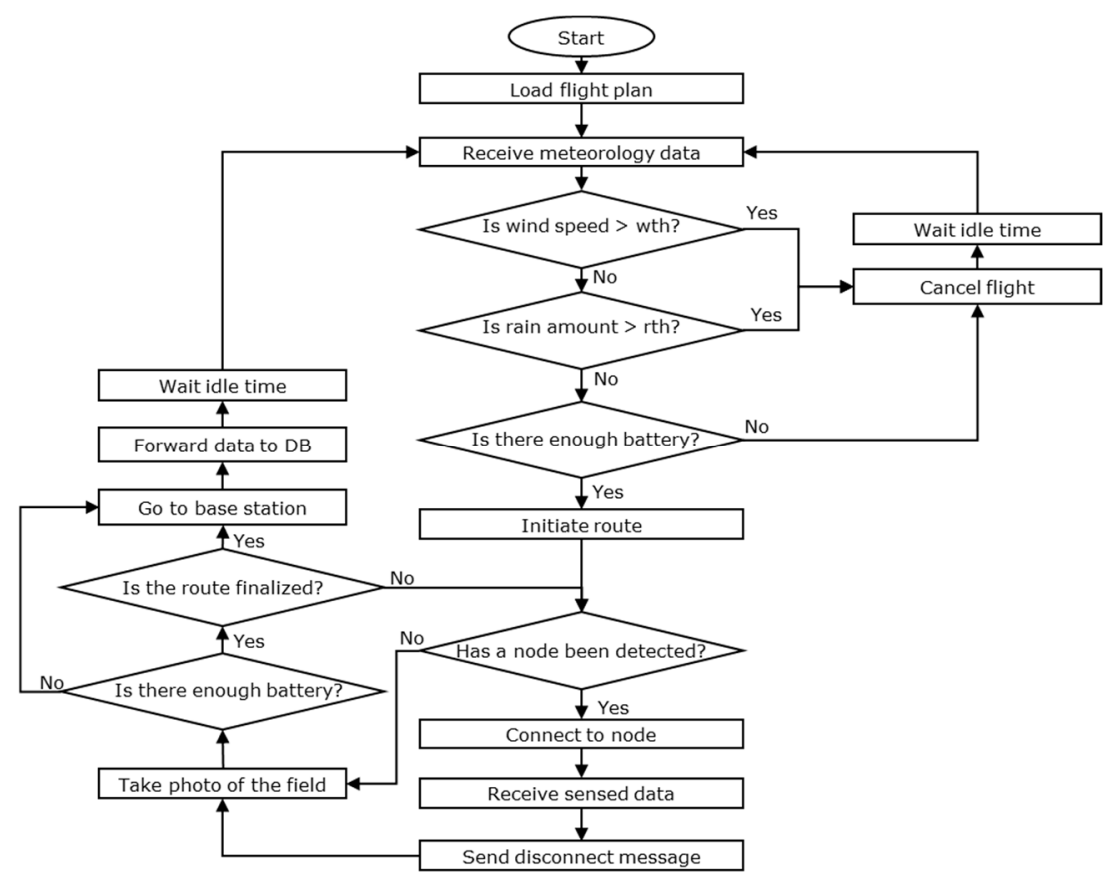

Figure 6. Algorithm of the drone.

The functioning algorithm of the node is presented in Figure 7. After the setup has been completed, the node starts gathering the data from the nodes and storing it on an SD card. If it is the scheduled time for the drone flight, the node gets activated to wait for the drone. If it is not the scheduled time, the node goes into sleep mode for the time specified in the setup parameters. If a drone is detected, all the data stored on the SD card are forwarded to the drone. When the node receives a disconnect message, the node disconnects from the drone and deletes all the data stored in the SD card. Then, the node goes into sleep mode for the time stipulated on the settings so as to save energy and to avoid the drone having interferences with other nodes. While the node does not detect the drone, it checks if the maximum time activated time is reached to determine if it needs to go to sleep mode. This way, the node is not constantly activated if the drone decides to cancel the flight due to weather conditions. Then, it keeps gathering the data from the sensors each time the time interval between measures loaded from the setup has been reached.

The message exchange between the elements of the architecture is presented in Figure 8. The drone sends beacons so the nodes can detect it and ask for a connection. When the connection establishment is performed, the node sends the data to the drone. The drone then sends an Acknowledgment (ACK) and a Disconnect message to indicate that the node should go into sleep mode for the stipulated time. After that, the node sends an ACK to the drone to indicate that the Disconnect message has been received correctly. The process is repeated with all the nodes deployed on the field within the coverage area of the drone as it follows its route. When the node reaches the base station, the data are forwarded to the database, and the database confirms the reception of the data with an ACK. 


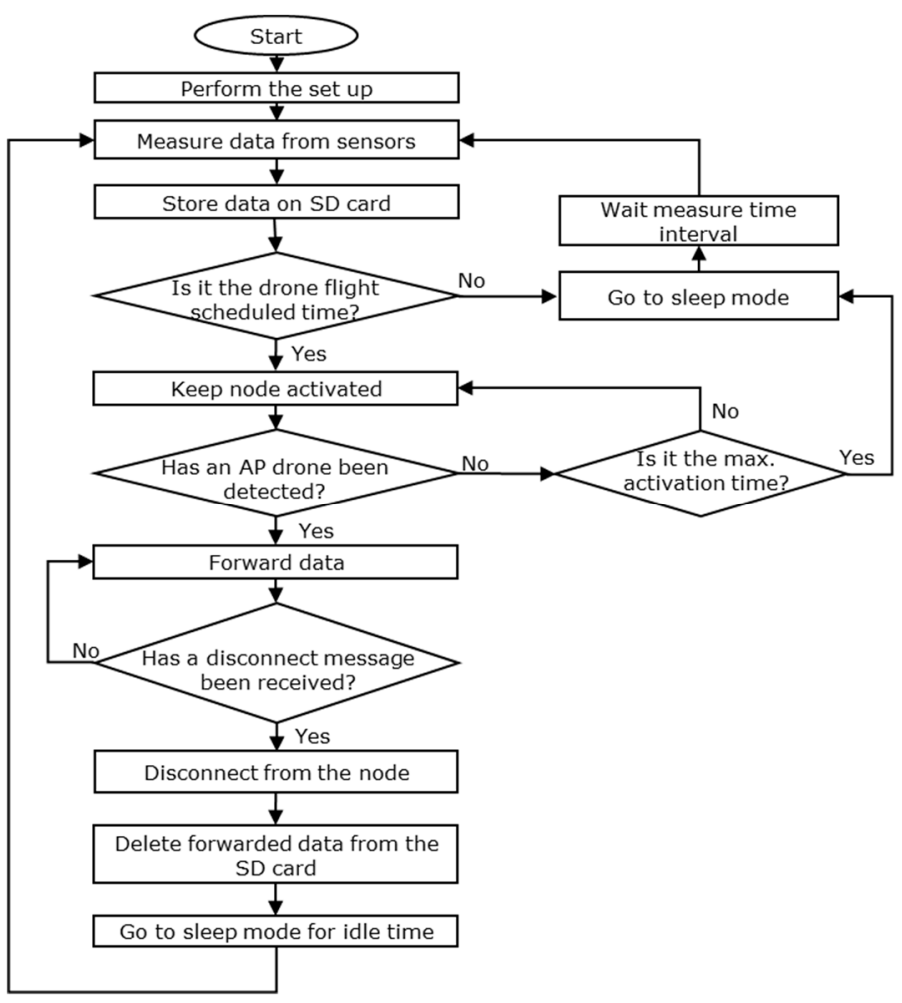

Figure 7. Algorithm of the node.

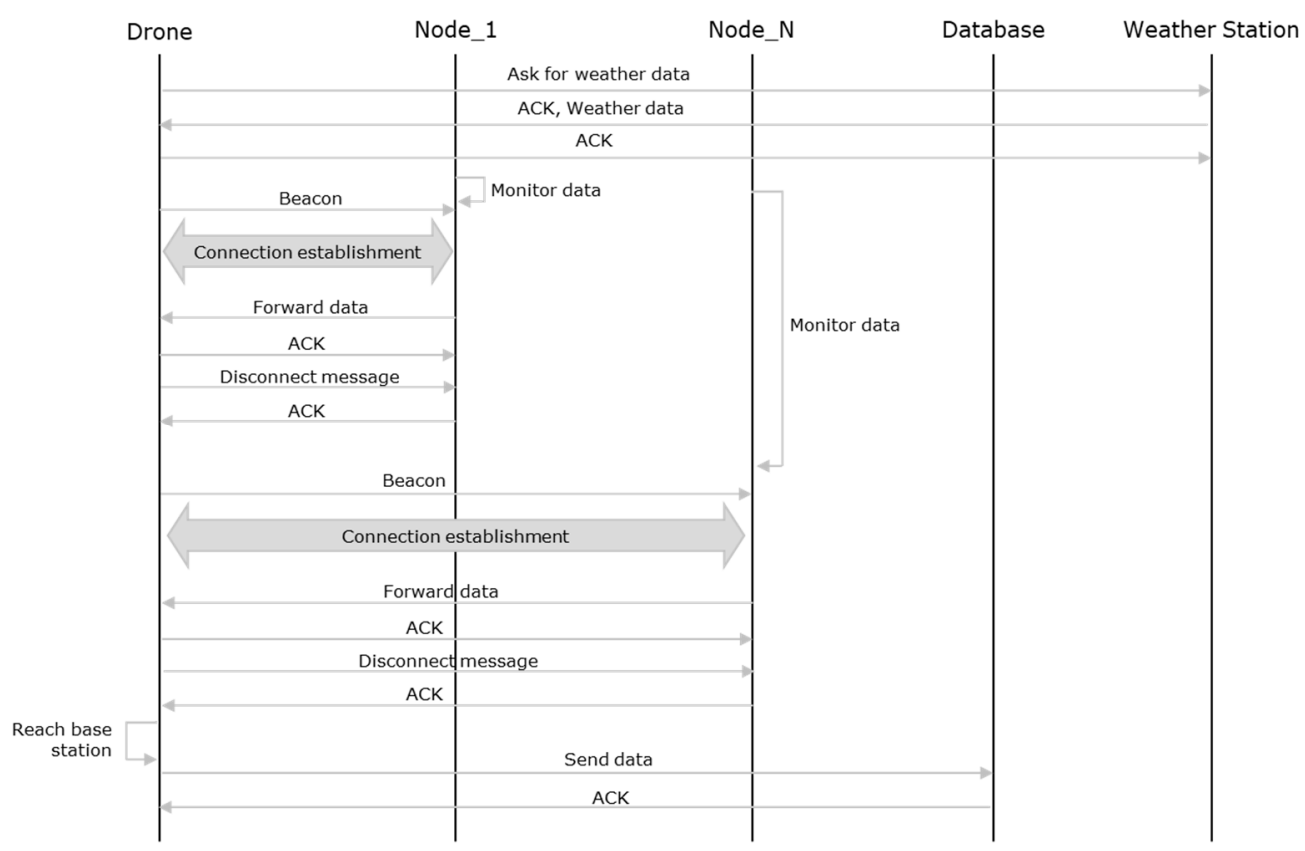

Figure 8. Message exchange between the elements of the architecture.

\section{Results}

In this section, we are going to analyze the theoretical values obtained after applying the equations described in Section 3.3. Furthermore, the energy consumption of the drone is analyzed as well.

\subsection{Coverage Analysis}

In this subsection, we first calculate the time during which a node has coverage from the gateway. Then, we calculate from those cases and with different bandwidth the amount of exchanged information 
between the node and the gateway and evaluate if this is enough to send the data stored in the node during the day.

Before starting to analyze the theoretical results, some assumptions must be made related to the connection and the density of nodes on the soil.

- First, we must consider the time required to establish the connection. We performed tests in real environments to determine the time required by Arduino nodes to establish the connection between each other. The results showed connection establishment times ranging between 2 and $4 \mathrm{~s}$. To ensure the connection of the nodes, we will consider the worst-case scenario of connection time of $4 \mathrm{~s}$. Since the data are forwarded after the connection establishment, we will consider $5 \mathrm{~s}$ of total required time for connection establishment and data transmission. Therefore, all the combinations of $d c$ and $f h$ that give, as a result, a time in coverage equal to or less than $5 \mathrm{~s}$ are considered as unfeasible scenarios for connection. Since the current velocities in WiFi have increased in the last years and the gathered data by the sensors are small, we can consider that all the information can be sent in this period of $5 \mathrm{~s}$.

- Moreover, all the coverage areas do not have the same properties in terms of signal strength. The further points have lower Received Signal Strength Indicator (RSSI) values, and the connection will be difficult in those situations. Nonetheless, the estimation of the effects of RSSI on the establishment of the connection is not the purpose of this paper.

- Finally, regarding the density of nodes, we must consider the number of nodes that will be able to connect to the drone at the same moment and that have to share their time in coverage. There is a different type of scenario regarding node density in precision agriculture. The densest cases are related to the intensive agriculture of fruit-bearing trees such as orchards. The farmers used to grow their trees in a density of one tree each 16 to $20 \mathrm{~m}^{2}$. In the case that we have one node per tree, the node density will be one node each 16 to $20 \mathrm{~m}^{2}$. Nonetheless, this is not usual, since the conditions of the soil and irrigation techniques are relatively homogeneous. Therefore, we can expect that in the densest networks, we have one node every three or four trees, having a density of one node each $60 \mathrm{~m}^{2}$. Other scenarios can include cereal or energetic crops. In these cases, the crops create a uniform soil coverage, and it is not possible to differentiate the individual plants. Moreover, as the outcomes of these crops are much lower than in the case of fruit-bearing trees, the investment in precision agriculture is lower. In addition, if we consider that most of the cereals and energetic crops do not need irrigation, the node density can be further lower. It is no exaggeration to say that in these cases, we can have only one node in each field having node densities of one each $5000 \mathrm{~m}^{2}$ or even more. In between both cases, we can find another example of fruit-bearing trees as olive trees. The density of trees in the field is lower than in the case of orchards. Moreover, since no irrigation systems are used in the culture of olive trees, the monitoring requirements are lower. Thus, we can expect densities of one node each $750 \mathrm{~m}^{2}$ in the cropping of this type of crop. Nevertheless, the final density will be a factor that the farmer will define. To select the density of the nodes, the farmer will consider the environmental parameters (soil proprieties, homogeneity of the terrain, and past climate events), culture parameters (crop resilience, irrigation requirements, and susceptibility to specific diseases or pests among others), and economic constraints (benefits of the crops and the required investment).

Therefore, and to facilitate the comprehension of the results section, we detail the included parameters and their range in our model in Table 3. In Table 3, we describe if the parameter is considered as a fixed parameter or not, which indicates whether this parameter is previously defined by the scenario or not. The defined parameters are the node density, the flying parameters (velocity and height), and the required time for communication. Furthermore, we have detailed the calculated parameters in our model based on the abovementioned variables. 
Table 3. Parameters included in our model.

\begin{tabular}{ccccc}
\hline Parameter & Fixed Parameter & Acronym & Units & Range \\
\hline Flying height & Yes & $f h$ & $(\mathrm{~m})$ & 4 to 104 \\
\hline Flying velocity & Yes & $f v$ & $(\mathrm{~m} / \mathrm{s})$ & 1 to 20 \\
\hline Drone coverage & No & $d c$ & (m) & 25 to 200 \\
\hline Node density & Yes & - & (nodes $\left./ \mathrm{m}^{2}\right)$ & 60 to 5000 \\
\hline Time in coverage & No & - & $(\mathrm{s})$ & Calculated \\
\hline $\begin{array}{c}\text { Required time for } \\
\text { communication }\end{array}$ & Yes & - & (nodes) & Calculated \\
\hline Nodes in coverage & No & - & No Units & Calculated \\
\hline Connection feasibility & No & &
\end{tabular}

Now, we are going to analyze the results of applying the equations to calculate the time in coverage for different scenarios. The time in coverage of a node placed on the soil when the drone is moving at $20 \mathrm{~m} / \mathrm{s}$ can be seen in Figure 9. The higher the $d c$, the higher the time in coverage. The maximum time in coverage is $20 \mathrm{~s}$ in the case of $d c=200 \mathrm{~m}$. The $f h$ has a relatively low impact in the time in coverage for gateways with $d c$ values of 150 to $200 \mathrm{~m}$. The increase of $f h$ from 0 to $100 \mathrm{~m}$ reduces the time in coverage of less than $25 \%$. For the drone with a $d c$ of a $25 \mathrm{~m}$ event with the lower $f h$, the time in coverage is only $4 \mathrm{~s}$, which makes the correct establishment of the communication and the data sending difficult. Thus, assuming this minimum time for establishing the connection, at $f v$ of $20 \mathrm{~m} / \mathrm{s}$, the gateways with a $d c$ of $25 \mathrm{~m}$ cannot be used, no matter their $f h$. When the used gateway has a $d c$ of $50 \mathrm{~m}$, the maximum possible $f h$ is $39 \mathrm{~m}$. For $d c$ values of 75 and $100 \mathrm{~m}$, they can be used with $f h$ values from 4 to $64 \mathrm{~m}$ and 4 to $89 \mathrm{~m}$, respectively.

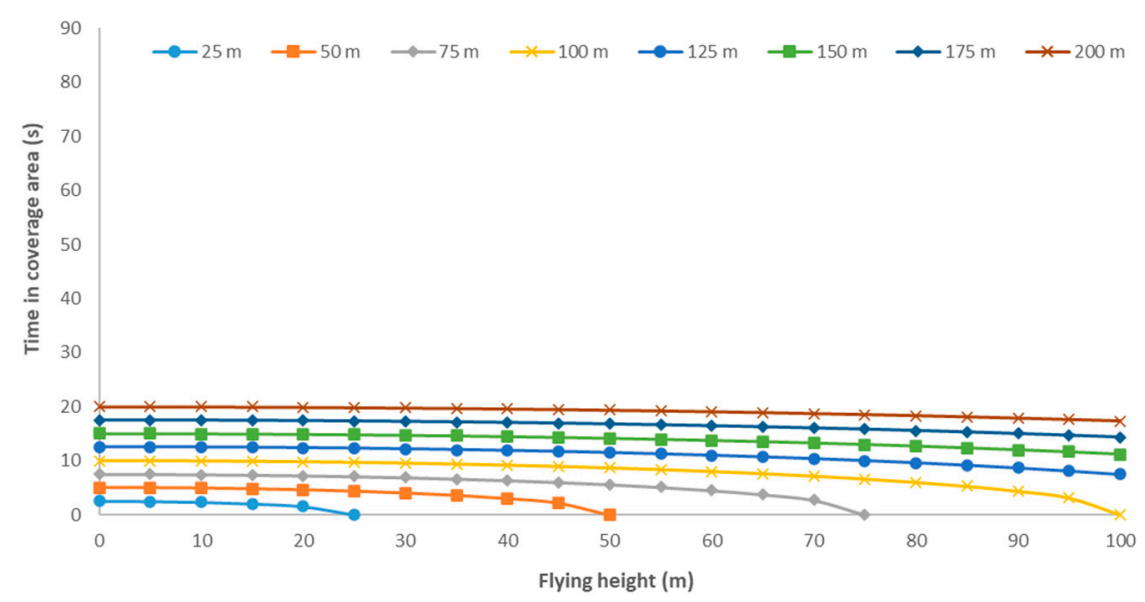

Figure 9. Time in coverage when a drone flies at $20 \mathrm{~m} / \mathrm{s}$ and different $d c$.

Following, the time in coverage for $f v=15 \mathrm{~m} / \mathrm{s}$ is presented in Figure 10. Compared with Figure 9 , as the drone is moving slowly, the time in coverage increases. The highest time in coverage for this scenario is $27 \mathrm{~s}$, which is $7 \mathrm{~s}$ more than in the previous case. For the minimum $d c$, the time in coverage when the $f h$ is the lesser is the same as in the previous case, $4 \mathrm{~s}$. For this combination of $d c$ and $f h$, the decrease of $f v$ does not produce a relevant change in the time in coverage. Thus, with a $d c$ of $25 \mathrm{~m}$, the communication with this velocity is not possible, no matter the $f h$. For the other $d c$ (50 to $100 \mathrm{~m}$ ), the maximum $f h$ offers enough time in coverage to ensure that the communication increases from 34 to $39 \mathrm{~m}(d c=50 \mathrm{~m})$, from 64 to $69 \mathrm{~m}(D C=75 \mathrm{~m})$, and from 89 to $94 \mathrm{~m}(d c=100 \mathrm{~m})$. 


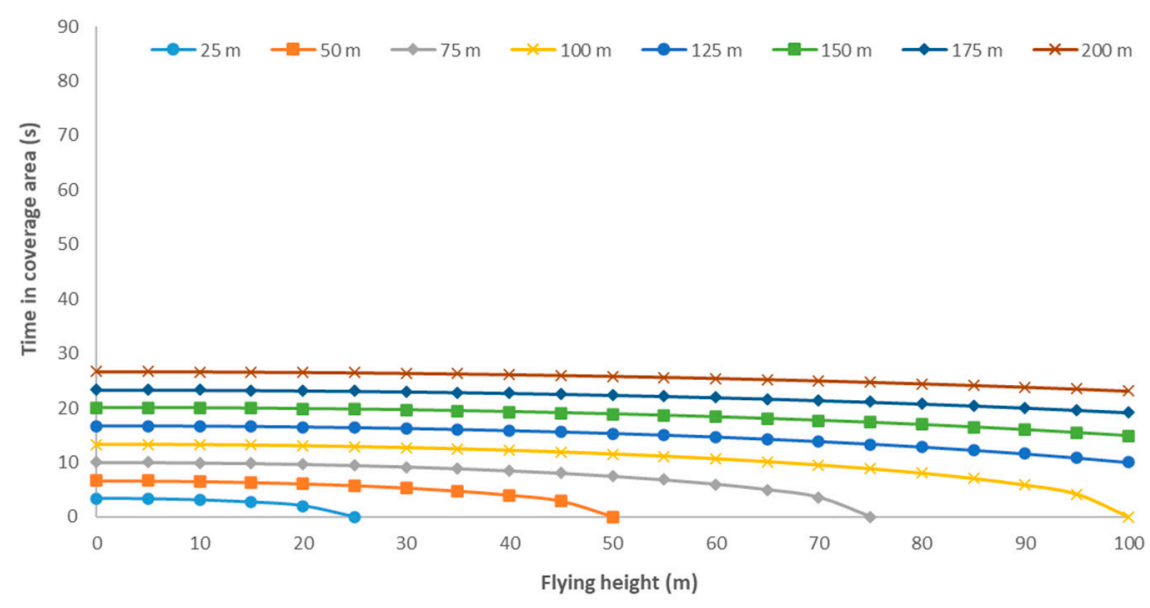

Figure 10. Time in coverage when a drone flies at $15 \mathrm{~m} / \mathrm{s}$ and different $d c$.

The results of time in coverage when the drone flies at $10 \mathrm{~m} / \mathrm{s}$ can be seen in Figure 11. In this case, the maximum time in coverage is $40 \mathrm{~s}$. On the other hand, form the minimum $d c$ and $f h$, the time in coverage is $5 \mathrm{~s}$ and can be used for receiving data from one node. With this fo, the maximum $f h$ for different $d c$ values increases significantly compared with previous velocities; for $d c=25,5 \mathrm{~m}$, the maximum $f h$ are $14,44 \mathrm{~m}$. Nonetheless, for $d c$ values of 75 and $100 \mathrm{~m}$, the maximum $f h$ is the same as in the previous velocities, and for $d c$ values higher than $100 \mathrm{~m}$, the communication is feasible at all the $f h$.

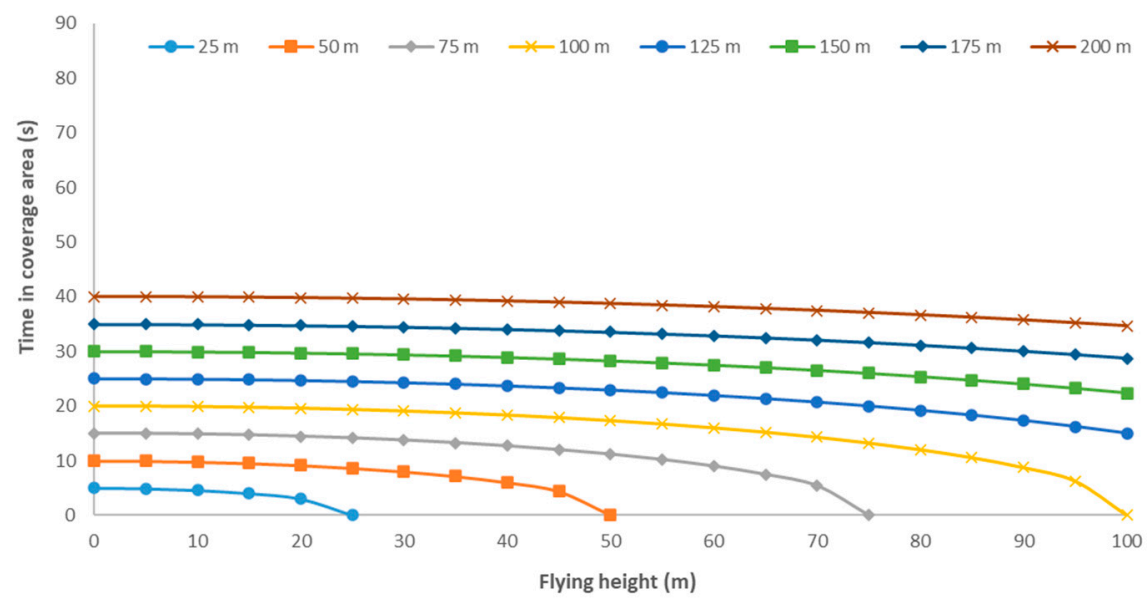

Figure 11. Time in coverage when a drone flies at $10 \mathrm{~m} / \mathrm{s}$ and different $d c$.

Following, in Figure 12, we can see the theoretical values of time in coverage for $f v=5 \mathrm{~m} / \mathrm{s}$. The maximum time in coverage increases to $80 \mathrm{~s}$ with $d c$ of $200 \mathrm{~m}$ and $f h$ of $4 \mathrm{~m}$. For the $d c$ of $25 \mathrm{~m}$, the maximum $f v$ where it is possible to establish a communication with a single node is $19 \mathrm{~m}$. For other $d c$ in all the cases where there is coverage for the sensor, the time in coverage is high enough to establish the connection and communicate the data.

In Figures 2-12, we presented the time in coverage of a single node and evaluated if this node will be able to transmit the information or not according to the required time to establish the connection and send data, which has been set in $5 \mathrm{~s}$. Next, we are going to analyze for each combination of $d c$ and $f h$ the area in the soil which has coverage. Then, according to the aforementioned node densities in Table 3, we calculate the number of nodes that will have coverage in a certain period and need to send their data to the gateway. According to the time in coverage, the minimum required time to establish a connection, send the data, and close the connection, and the number of nodes, we estimate if the drone can be used to receive all the data of the WSN or not. The summary of different considered 
scenarios and the results in terms of the success or not of the connection are presented in Figure 13. In Figure 13, we can identify in different rectangles the different scenarios, which combine different node densities and $f v$. In each scenario, we can consider the combination of $d c$ and $f h$ in the $x$ and y-axis. Thus, we cover all the parameters that affect the success or not of the gathering of all data stored in the nodes placed in the soil. The success of the connection is indicated in colors; the area colored in gray indicates that there is no coverage (NC) for this combination of $f h$ and $d c$. This is found when the $f h$ is higher than the $d c$. The areas in red represent combinations of $d c$ and $f h$ when even that we have coverage, the time in coverage is too short for ensuring the transmission of data from all the nodes. It means that the time in coverage of the nodes contained in the area in coverage is lower than $5 \mathrm{~s}$ for each one and the gathering of data contained in the nodes cannot be attained. Combinations colored in yellow represent the combination of $d c$ and $f h$ that can be used to receive the data but with very adjusted time. Therefore, if an unexpected problem such as punctual loss of connection appears during the communications, it can endanger the collection of the data of certain nodes. In green, we present the optimal combination of $d c$ and $f h$ that ensure the data gathering.

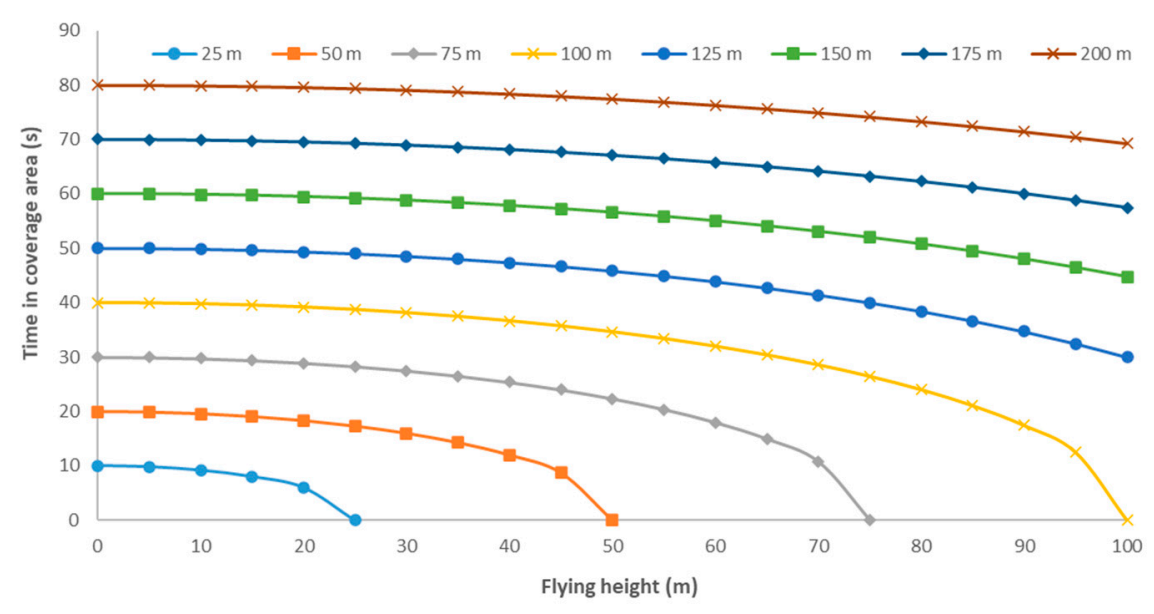

Figure 12. Time in coverage when a drone flies at $5 \mathrm{~m} / \mathrm{s}$ and different $d c$.

According to Figure 13, we can determine for a given $f v, f h$, and node density if we will be able to communicate and receive the data from all of our nodes or not with different types of $d c$. Now, we are going to analyze the different scenarios; for the scenario with the maximum node density (1 node each $60 \mathrm{~m}^{2}$ ), there is only one combination that allows the communication. This combination is found for the lowest $f v(1 \mathrm{~m} / \mathrm{s})$ at $f h=24 \mathrm{~m}$ and $d c=25 \mathrm{~m}$. The result of this combination of parameters is good coverage (yellow). For the other node densities, we can find more combinations. For node densities of one node every $750 \mathrm{~m}^{2}$ and the maximum $f v$, no combination allows the communication. For other fh of 15 and $10 \mathrm{~m} / \mathrm{s}$, few combinations allow a good connection. Meanwhile, when the fo decrease to $5 \mathrm{~m} / \mathrm{s}$, we can identify some combinations of $f h$ and $d c$ that result in an optimal connection $(f h=24 \mathrm{~m}$ and $d c=25 \mathrm{~m}$ ). For the lowest $f v$, several combinations allow good and optimal connectivity. Finally, for the scenario with the lowest density of nodes (one node every $5000 \mathrm{~m}^{2}$ ), we can identify some combinations that allow optimal connection even with the highest $f v$ with $f$ h equal or smaller than $100 \mathrm{~m}$. For the other fo ( 15 to $1 \mathrm{~m} / \mathrm{s}$ ), several combinations of $f h$ and $d c$ ensure that the drone can act as a mobile gateway and gather the data of nodes placed in the soil.

In case that none of the combinations of the given parameters ( $f h, f v$, and node density) with different $d c$ values offer us a good (yellow) or optimal (green) solution, it will be necessary to evaluate if the possibility to modify the given parameters (fixed parameters) exists. For example, decreasing the $f v$ or increasing the $f h$ can be useful to ensure communication; meanwhile, we maintain the original purpose of the drone. These adjustments must be carefully considered to guarantee that the original purpose of the drone surveillance of the crop is possible. To do so, it will be necessary to evaluate 
the loss of image resolution due to the increment in the $f h$ and the reduction of overlapping between obtained images due to $f h$.
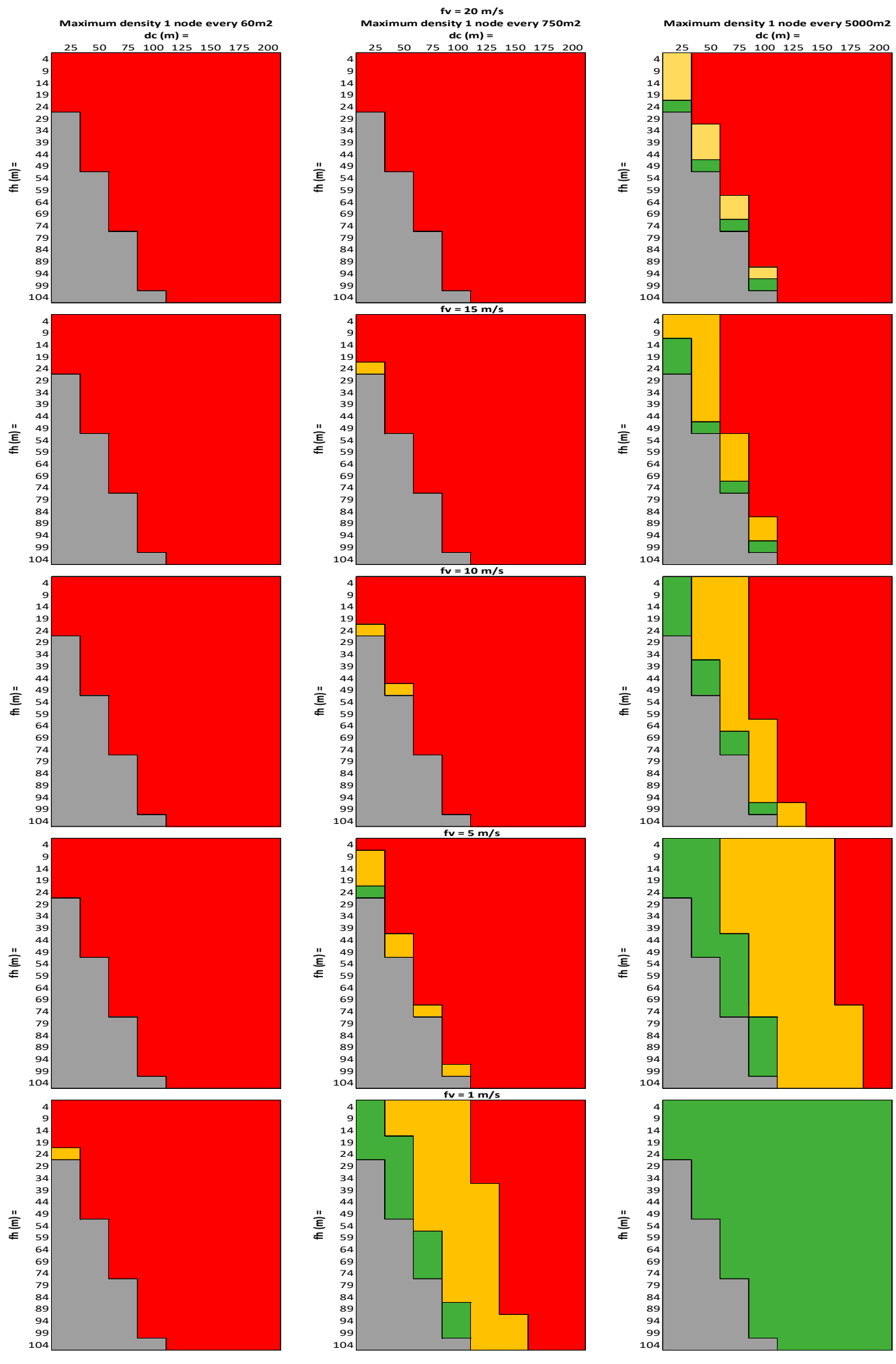

No Coverage

Not enough time $\square$ Good connection

Optimal Connection

Figure 13. Summary of communication in different scenarios: gray is no coverage (NC), red is not enough time in coverage. 
Otherwise, in case there is no possibility to change the given parameters, it will be necessary to use some other communication process in the nodes placed on the soil. For example, it will be possible to use a clustering algorithm to communicate all the gathered data from the cluster to the cluster head, and this cluster head sends the data to the node. This will minimize the time consumed to send the data, as fewer processes of communication establishment must be done. Nonetheless, this solution is limited to the coverage of WiFi antennas of nodes placed in the soil, and it can only be applied in cases with high node densities.

\subsection{Energy Consumption}

In this subsection, the energy consumption of the drone is presented.

The energy consumption of a quadcopter drone is presented in Equation (8), where the minimum flight power for hovering at the lowest height $(\beta)$ is 30, the multiplier for the velocity of the motor $(\alpha)$ is 10.5 , and the maximum power that the motor can achieve $\left(P_{\max }\right)$ is 85 , according to [51]. The flying time $(t)$ will be set to $20 \mathrm{~min}$ as it is the typical nominal endurance for quadcopter drones.

$$
\text { Energy }=(\beta+\alpha * f h) t+P_{\max }(f h / f v)
$$

For quadcopter drones, the energy consumption of the drone is highly dependent on the flying height. To increase the coverage time, some authors have presented proposals for flight plans where the drone circles the node on the ground until all the data are transmitted. In our case, we consider the transmission of small amounts of data gathered from soil monitoring sensors. Therefore, that type of flight plan is not necessary for our scenario.

The energy consumption of the quadcopter drone for a flying time of $20 \mathrm{~min}$ is presented in Figure 14. The energy consumption is height dependent, and the speed of the drone barely creates a difference in energy consumption. Considering that flying heights between 15 and $25 \mathrm{~m}$ provide better coverage, the selection of a flying height within that range would minimize the energy consumption while maximizing the coverage of the node placed at the drone.

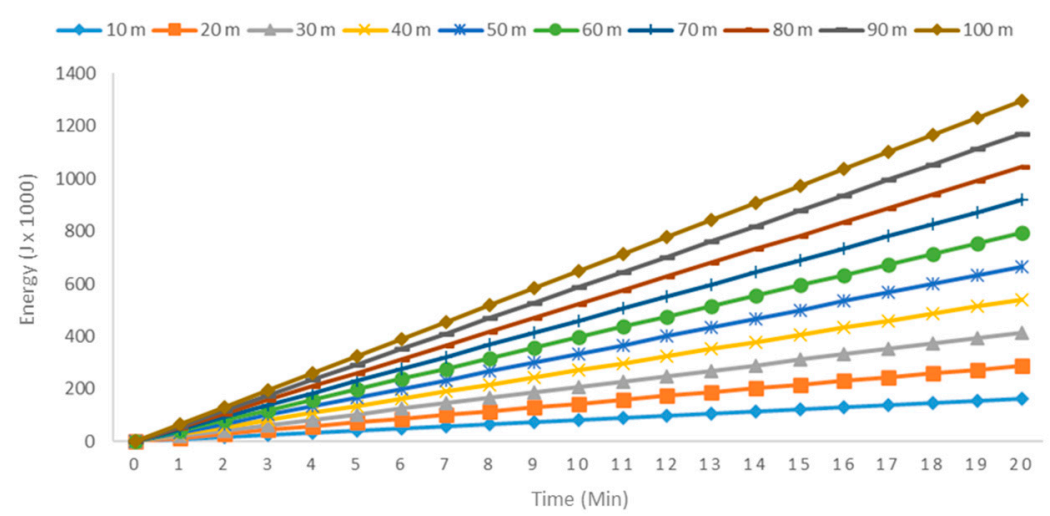

Figure 14. Energy consumption of a quadcopter drone at $10 \mathrm{~m} / \mathrm{s}$ for different $f h$.

Considering the different node densities studied in this paper, the approximated number of nodes that the drone can cover in a flight of $20 \mathrm{~min}$ at different $f v$ values is presented in Table 4 . This calculation was performed determining the space covered by the drone at each fo taking into account that the nodes are placed at the center of a square sector of $60 \mathrm{~m}^{2}, 750 \mathrm{~m}^{2}$ or $5000 \mathrm{~m}^{2}$, according to the node density, and the drone flies over them in a straight line to gather the information. Therefore, for a node density of one node per $60 \mathrm{~m}^{2}$ the number of nodes that can be covered is considerably greater than that of the other two configurations. 
Table 4. Nodes covered in a 20-min flight for different $f v$ and node densities.

\begin{tabular}{|c|c|c|c|c|c|}
\hline Velocity & $1 \mathrm{~m} / \mathrm{s}$ & $5 \mathrm{~m} / \mathrm{s}$ & $10 \mathrm{~m} / \mathrm{s}$ & $15 \mathrm{~m} / \mathrm{s}$ & $20 \mathrm{~m} / \mathrm{s}$ \\
\hline 1 node per $60 \mathrm{~m}^{2}$ & 19 & 99 & 199 & 299 & 399 \\
\hline 1 node per $750 \mathrm{~m}^{2}$ & - & 7 & 15 & 23 & 31 \\
\hline 1 node per $5000 \mathrm{~m}^{2}$ & - & - & 1 & 2 & 3 \\
\hline
\end{tabular}

\section{Conclusions and Future Work}

The EU has among its 2020 policies a Common Agricultural Policy to ensure food availability for the population of the EU. Precision Agriculture (PA) is encompassed in these policies, as it aids in optimizing the crops and facilitating crop management using technology. Sensor nodes and drones are some of the technologies that can be utilized in PA to monitor the crops in real time. In this paper, we have considered the use of remote sensing drones as mobile gateways to provide a guide to determine the best drone parameters for successful data transmission between sensor nodes and the gateway in PA systems to monitor and manage crops. The drone gathers the data from the sensor nodes by flying over them and connecting wirelessly to them using WiFi.

We have defined some parameters such as the $f h$ or the $f v$ as fixed parameters, while others such as the antenna (or $d c$ ) might be adapted to reach the connectivity. Different scenarios were simulated to determine the optimal drone parameters for the drone to be able to gather the data from the sensor nodes. The results indicate that for the highest node density, there is only one case in which the drone can be used when the drone has a flying height of $24 \mathrm{~m}$ or lower and velocities equal or lower to $1 \mathrm{~m} / \mathrm{s}$, and we include an antenna with a coverage of $25 \mathrm{~m}$. For the rest of the node densities, we can find several combinations that ensure that the drone can be efficiently used as a mobile gateway. Nonetheless, in maximum flying velocity, no connectivity is achieved for the medium node density.

For future work, we will perform real tests with different nodes, different wireless technologies such as ZigBee, and different soil node settings. We will also evaluate the performance of remote sensing drones utilized as mobile gateways with the implementation of fault-tolerance and energy-saving algorithms for its use in smart irrigation systems, as it is detailed in [52]. In addition, we will measure how the extra weight due to the node and antenna affects the flying capabilities of different drones.

Author Contributions: Methodology, L.G., L.P., J.M.J.; formal analysis, L.G.; investigation, L.G., L.P., J.M.J.; resources, P.V.M.; writing-original draft preparation, L.G., L.P., J.M.J.; writing-review and editing, J.L., P.L.; supervision, J.L., P.L.; project administration, J.L., P.V.M., P.L.; funding acquisition, J.L., P.V.M., P.L. All authors have read and agreed to the published version of the manuscript.

Funding: This work is partially founded by the European Union with the "Fondo Europeo Agrícola de Desarrollo Rural (FEADER) -Europa invierte en zonas rurales", the MAPAMA, and Comunidad de Madrid with the IMIDRA, under the mark of the PDR-CM 2014-2020" project number PDR18-XEROCESPED, by the European Union through the ERANETMED (Euromediterranean Cooperation through ERANET joint activities and beyond) project ERANETMED3-227 SMARTWATIR, and by Conselleria de Educación, Cultura y Deporte with the Subvenciones para la contratación de personal investigador en fase postdoctoral, grant number APOSTD/2019/04.

Conflicts of Interest: The authors declare no conflict of interest.

\section{References}

1. Agriculture and Rural Development Agriculture and Rural Development. Available online: https://ec.europa. eu/agriculture/cap-post-2013/ (accessed on 3 December 2019).

2. Kropff, M.; Wallinga, J.; Lotz, L. Modelling for Precision Weed Management. In Proceedings of the Ciba Foundation Symposium 210-Precision Agriculture: Spatial and Temporal Variability of Environmental Quality, Chichester, UK, 27 September 2007; pp. 182-207. [CrossRef]

3. Earl, R.; Wheeler, P.; Blackmore, S.; Godwin, R.J. Precision Farming: The Management of Variability. AGRIS 2013, 51, 18-23.

4. Srinivasan, A. Handbook of Precision Agriculture: Principles and Applications; CRC Press: New York, NY, USA, 2006; ISBN 9781560229551. 
5. Toth, C.; Jóźków, G. Remote sensing platforms and sensors: A survey. ISPRS J. Photogramm. Remote Sens. 2016, 115, 22-36. [CrossRef]

6. Pajares, G. Overview and Current Status of Remote Sensing Applications Based on Unmanned Aerial Vehicles (UAVs). Photogramm. Eng. Remote Sens. 2015, 81, 281-330. [CrossRef]

7. Maes, W.H.; Steppe, K. Perspectives for Remote Sensing with Unmanned Aerial Vehicles in Precision Agriculture. Trends Plant Sci. 2019, 24, 152-164. [CrossRef]

8. Psirofonia, P.; Samaritakis, V.; Eliopoulos, P.; Potamitis, I. Use of Unmanned Aerial Vehicles for Agricultural Applications with Emphasis on Crop Protection: Three Novel Case-studies. Int. J. Agricult. Sci. Technol. 2017, 5, 30-39. [CrossRef]

9. Agriculture Drones Market by Offering (Hardware and Software \& Services), Application (Precision Farming, Livestock Monitoring, Precision Fish Farming, and Smart Greenhouse), Component, and Geography-Global Forecast to 2024. Available online: https://www.marketsandmarkets. com/Market-Reports/agriculture-drones-market-23709764.html?gclid=CjwKCAiA-P7xBRAvEiwAowVaRPLzQ4x9YHOwUyC4e-PBfjvjpkB4Bqx9WWIt6S-1M0FsKvUcbqLdxoC_VcQAvD_BwE (accessed on 3 February 2020).

10. Cunliffe, A.M.; Brazier, R.E.; Anderson, K. Ultra-fine grain landscape-scale quantification of dryland vegetation structure with drone-acquired structure-from-motion photogrammetry. Remote Sens. Environ. 2016, 183, 129-143. [CrossRef]

11. Zhang, J.; Hu, J.; Lian, J.; Fan, Z.; Ouyang, X.; Ye, W. Seeing the forest from drones: Testing the potential of lightweight drones as a tool for long-term forest monitoring. Biol. Conserv. 2016, 198, 60-69. [CrossRef]

12. Urbahs, A.; Jonaite, I. Features of the use of unmanned aerial vehicles for agriculture applications. Aviation 2013, 17, 170-175. [CrossRef]

13. Raeva, P.L.; Šedina, J.; Dlesk, A. Monitoring of crop fields using multispectral and thermal imagery from UAV. Eur. J. Remote Sens. 2019, 52, 192-201. [CrossRef]

14. Stehr, N.J.; Justen, V. Drones: The Newest Technology for Precision Agriculture. Nat. Sci. Educ. 2015, 44, 89-91. [CrossRef]

15. Kurkute, S.R.; Deore, B.D.; Kasar, P.; Bhamare, M.; Sahane, M. Drones for Smart Agriculture: A Technical Report. Int. J. Res Appl. Sci. Eng. Technol. 2018, 6, 341-346. [CrossRef]

16. Puri, V.; Nayyar, A.; Raja, L. Agriculture drones: A modern breakthrough in precision agriculture. J. Stat. Manag. Syst. 2017, 20, 507-518. [CrossRef]

17. Valente, J.; Sanz, D.; Barrientos, A.; del Cerro, J.; Ribeiro, A.; Rossi, C. An Air-Ground Wireless Sensor Network for Crop Monitoring. Sensors 2011, 11, 6088-6108. [CrossRef]

18. Hunt, E.R.J.; Daughtry, C.S.T. What good are unmanned aircraft systems for agricultural remote sensing and precision agriculture? Int. J. Remote Sens. 2018, 39, 5345-5376. [CrossRef]

19. Tsouros, D.C.; Bibi, S.; Sarigiannidis, P.G. A Review on UAV-Based Applications for Precision Agriculture. Information 2019, 10, 349. [CrossRef]

20. Daponte, P.; De Vito, L.; Glielmo, L.; Iannelli, L.; Liuzza, D.; Picariello, F.; Silano, G. A review on the use of drones for precision agriculture. IOP Conf. Ser. Earth Environ. Sci. 2019, 275, 012022. [CrossRef]

21. Boehm, F.; Schulte, A. Air to ground sensor data distribution using IEEE80211N Wi-Fi network. In Proceedings of the 2013 IEEE/AIAA 32nd Digital Avionics Systems Conference (DASC), East Syracuse, NY, USA, 5-10 October 2013; pp. 4-10. [CrossRef]

22. Stek, T.D. Drones over Mediterranean landscapes. The potential of small UAV's (drones) for dite detection and heritage management in archaeological survey projects: A case study from Le Pianelle in the Tappino Valley, Molise (Italy). J. Cult. Herit. 2016, 22, 1066-1071. [CrossRef]

23. Marín, J.; Parra, L.; Rocher, J.; Sendra, S.; Lloret, J.; Mauri, P.V.; Masaguer, A. Urban Lawn Monitoring in Smart City Environments. J. Sens. 2018, 8743179. [CrossRef]

24. Ojha, T.; Misra, S.; Raghuwanshi, N.S. Wireless sensor networks for agriculture: The state-of-the-art in practice and future challenges. Comp. Electron. Agric. 2015, 118, 66-84. [CrossRef]

25. Tzounis, A.; Katsoulas, N.; Bartzanas, T.; Kittas, C. Internet of Things in agriculture, recent advances and future challenges. Biosyst. Eng. 2017, 164,31-48. [CrossRef]

26. Rehman, A.; Abbasi, A.Z.; Islam, N.; Shaikh, Z.A. A Review of Wireless Sensors and Networks' Applications in Agriculture. Comp. Stand. Interfaces 2014, 36, 263-270. [CrossRef] 
27. Ruiz-Garcia, L.; Lunadei, L.; Barreiro, P.; Robla, J.I. A Review of Wireless Sensor Technologies and Applications in Agriculture and Food Industry: State of the Art and Current Trends. Sensors 2009, 9, 4728-4750. [CrossRef] [PubMed]

28. Barcelo-Ordinas, J.M.; Chanet, J.P.; Hou, K.M.; García-Vidal, J. A survey of wireless sensor technologies applied to precision agriculture. In Proceedings of the 9th European Conference on Precision Agriculture, Lleida, Spain, 7-11 July 2013; pp. 801-808. [CrossRef]

29. Srbinovska, M.; Gavrovski, C.; Dimcev, V.; Krkoleva, A.; Borozan, V. Environmental parameters monitoring in precision agriculture using wireless sensor networks. J. Clean. Prod. 2015, 88, 297-307. [CrossRef]

30. Yu, X.; Wu, P.; Han, W.; Zhang, Z. A survey on wireless sensor network infrastructure for agriculture. Comp. Stand. Interfaces 2013, 35, 59-64. [CrossRef]

31. Chaudhary, D.D.; Nayse, S.P.; Waghmare, L.M. Application of Wireless Sensor Networks for Greenhouse Parameter Control in Precision Agriculture. Int. J. Wirel. Mob. Netw. 2011, 3, 140-149. [CrossRef]

32. Escolar Díaz, S.; Carretero Pérez, J.; Calderón Mateos, A.; Marinescu, M.; Bergua Guerra, B. A novel methodology for the monitoring of the agricultural production process based on wireless sensor networks. Comp. Electron. Agricult. 2011, 76, 252-265. [CrossRef]

33. Zhu, Y.; Song, J.; Dong, F. Applications of wireless sensor network in the agriculture environment monitoring. Procedia Eng. 2011, 16, 608-614. [CrossRef]

34. Keshtgari, M.; Deljoo, A. A Wireless Sensor Network Solution for Precision Agriculture Based on ZigBee Technology. Wirel. Sens. Netw. 2012, 4, 25-30. [CrossRef]

35. Hwang, J.; Shin, C.; Yoe, H. Study on an Agricultural Environment Monitoring Server System using Wireless Sensor Networks. Sensors 2010, 10, 11189-11211. [CrossRef]

36. Garcia-Sanchez, A.; Garcia-Sanchez, F.; Garcia-Haro, J. Wireless sensor network deployment for integrating video-surveillance and data-monitoring in precision agriculture over distributed crops. Comp. Electron. Agricult. 2011, 75, 288-303. [CrossRef]

37. García, L.; Parra, L.; Jimenez, J.M.; Lloret, J.; Lorenz, P. Practical Design of a WSN to Monitor the Crop and its Irrigation System. Netw. Protoc. Algorithms 2018, 10, 35-52. [CrossRef]

38. Asadpour, M.; Giustiniano, D.; Hummel, K.A. From Ground to Aerial Communication: Dissecting WLAN 802.11 for the Drones. In Proceedings of the 8th ACM International Workshop on Wireless Network Testbeds, Experimental Evaluation \& Characterization, Miami, FL, USA, 30 September 2013; pp. 25-32.

39. Rosati, S.; Kruzelecki, K.; Traynard, L.; Rimoldi, B. Speed-Aware Routing for UAV Ad-Hoc Networks. In Proceedings of the Globecom 2013 Workshop-Wireless Networking and Control for Unmanned Autonomous Vehicles, Atlanta, GA, USA, 9-13 December 2013; pp. 1367-1373.

40. Rahman, A. Enabling Drone Communications with WiMAX Technology. In Proceedings of the 5th International Conference on Information, Intelligence, Systems and Applications, Chania, Greece, 7-9 July 2014; pp. 323-328.

41. Yuan, Z.; Huang, X.; Sun, L.; Jin, J. Software Defined Mobile Sensor Network for Micro UAV Swarm. In Proceedings of the 2016 IEEE International Conference on Control and Robotics Engineering, Singapore, Singapore, 2-4 April 2016; pp. 1-4.

42. Popescu, D.; Stoican, F.; Stamatescu, G.; Ichim, L.; Dragana, C. Advanced UAV-WSN System for Intelligent Monitoring in Precision Agriculture. Sensors 2020, 20, 817. [CrossRef] [PubMed]

43. Specifications of the WEMOS MINI DI. Available online: https://docs.wemos.cc/en/latest/d1/d1_mini.html (accessed on 3 February 2020).

44. Specifications of the Node MCU. Available online: https://joy-it.net/en/products/SBC-NodeMCU-ESP32 (accessed on 3 February 2020).

45. Specifications of the Arduino Mega. Available online: https://store.arduino.cc/arduino-mega-2560-rev3 (accessed on 3 February 2020).

46. Specifications of the Arduino UNO. Available online: https://store.arduino.cc/arduino-uno-rev3 (accessed on 3 February 2020).

47. Specifications of the Raspberry Pi Model B+. Available online: https://www.raspberrypi-spy.co.uk/2018/03/ introducing-raspberry-pi-3-b-plus-computer/ (accessed on 3 February 2020).

48. Anguera, J.; Perez, A. Teoría de Antenas, 1st ed.; Edicions UPC; Universitat Ramon Llull: Barcelona, Spain, 2008; ISBN 84-8301-625-7. 
49. Arjadi, R.H.; Candra, H.; Prananto, H.D.; Wijanarko, T.A.W. RSSI Comparison of ESP8266 Modules. In Proceedings of the 2018 Electrical Power, Electronics, Communications, Controls and Informatics Seminar, Batu, Indonesia, 9-11 October 2018; pp. 150-153.

50. Guillen-Perez, A.; Sanchez-Iborra, R.; Cano, M.; Sanchez-Aarnoutse, J.C.; Garcia-Haro, J. WiFi Networks on Drones. In Proceedings of the ITU Kaleidoscope: ICTs for a Sustainable World, Bangkok, Thailand, 14-16 November 2016; pp. 1-8.

51. Zorbas, D.; Di Puglia Pugliese, L.; Razafindralambo, T.; Guerreiro, F. Optimal drone placement and cost-efficient target coverage. J. Netw. Comp. Appl. 2016, 75, 16-31. [CrossRef]

52. Parra, L.; Rocher, J.; García, L.; Lloret, J.; Tomás, J.; Romero, O.; Rodilla, M.; Falco, S.; Sebastiá, M.T.; Mengual, J.; et al. Design of a WSN for Smart Irrigation in Citrus Plots with Fault-Tolerance and Energy-Saving Algorithms. Netw. Protoc. Algorithms 2018, 10, 95-115. [CrossRef]

(C) 2020 by the authors. Licensee MDPI, Basel, Switzerland. This article is an open access article distributed under the terms and conditions of the Creative Commons Attribution (CC BY) license (http://creativecommons.org/licenses/by/4.0/). 